\title{
"What really matters is the economic performance: Positioning tourist destinations by means of perceptual maps"
}




\section{$\Phi|R| E|A|$}

Institut de Recerca en Economia Aplicada Regional i Pública

Research Institute of Applied Economics

Universitat de Barcelona

Av. Diagonal, 690 • 08034 Barcelona

WEBSITE: www.ub.edu/irea/•CONTACT: irea@ub.edu

The Research Institute of Applied Economics (IREA) in Barcelona was founded in 2005, as a research institute in applied economics. Three consolidated research groups make up the institute: AQR, RISK and GiM, and a large number of members are involved in the Institute. IREA focuses on four priority lines of investigation: (i) the quantitative study of regional and urban economic activity and analysis of regional and local economic policies, (ii) study of public economic activity in markets, particularly in the fields of empirical evaluation of privatization, the regulation and competition in the markets of public services using state of industrial economy, (iii) risk analysis in finance and insurance, and (iv) the development of micro and macro econometrics applied for the analysis of economic activity, particularly for quantitative evaluation of public policies.

IREA Working Papers often represent preliminary work and are circulated to encourage discussion. Citation of such a paper should account for its provisional character. For that reason, IREA Working Papers may not be reproduced or distributed without the written consent of the author. A revised version may be available directly from the author.

Any opinions expressed here are those of the author(s) and not those of IREA. Research published in this series may include views on policy, but the institute itself takes no institutional policy positions. 
The present study aims to cluster the world's main tourist destinations according to the growth of the economic performance of the tourist activity and of the tourist and economic development experienced during the last decade. With this objective, we combine the information from a set of tourist and economic indicators for the main 45 tourist destinations over the period between 2000 and 2010. Destinations are ranked with respect to their average growth rate over the sample period. By assigning a numerical value to each country corresponding to its position, all the information is summarised into two components ("economic performance of tourist activity" and "tourist and economic development") via multivariate techniques for dimensionality reduction: multidimensional scaling (MDS) and categorical principal components analysis (CATPCA). By means of perceptual maps, we find that destinations can be clustered into four different groups. The first one, dominated by Western and Northern Europe markets, contains some of the top destinations (France, Spain and the United States). A second one, with a predominance of Mediterranean destinations (Cyprus, Greece, Italy and Israel), obtains high scores in both dimensions. In the third one, we find Cambodia and China, alongside Egypt and Turkey. Finally, a fourth group dominated by Eastern Europe destinations (Bulgaria, Croatia and Latvia) with low scores in both dimensions.

JEL classification: A12, C38, F43, M31, Z3, Z32

Keywords: Tourist destinations; Positioning; Perceptual maps; Multidimensional Scaling (MDS); Categorical Principal Components Analysis (CATPCA).

Oscar Claveria: Department of Econometrics, Statistics and Applied Economics. University of Barcelona, Diagonal 690, 08034 Barcelona, Spain. E-mail: oclaveria@ub.edu

\section{Acknowledgements}

We wish to thank Laura Muñoz and Jacinta García at the World Tourism Organization (UNWTO)

for providing us with the data used in this study. This paper has been partially financed by the project ECO2016-75805-R of the Spanish Ministry of Economy and Competitiveness. 


\section{Introduction}

Tourism is one of the fastest-growing economic sectors in the world, and it has turned into a key driver of socio-economic development. Travel and passenger transport represents $30 \%$ of the world's exports of services. The number of international tourist arrivals (overnight visitors) in 2015 increased by $4.6 \%$ to reach a total of 1186 million worldwide (UNWTO, 2016). While other commodity prices showed decreasing prices, international tourism receipts increased by 4.4\% in real terms in 2015 (UNWTO, 2016). Accordingly, tourist destinations have to make major efforts to develop and manage their brand within an increasingly competitive market (Mariani et al., 2014; Wang \& Pizam, 2011).

Countries worldwide are opening up to tourism. Consequently, emerging destinations are playing an increasingly important role in this competitive environment. According to the UNWTO (2015), arrivals in emerging destinations between 2010 and 2030 are expected to increase at twice the rate of those in advanced economies, reaching a $57 \%$ share of the market. Mature destinations in Northern and Western Europe and North America are expected to experience a comparatively slower growth during the next two decades. On the contrary, Africa, the Middle East, and especially Asia and the Pacific are the regions expected to grow faster. As a result, tourism in emerging markets is drawing increasing attention (Cohen et al., 2014). Despite the growing interest in emerging markets, most tourism research still focus on the world's top tourist destinations (Claveria, 2016; UNWTO, 2015).

This study aims to shed some light on the evolution of tourism trends during the last decade in the world's main 45 tourist destinations. We use the methodology proposed by Claveria (2016) to position and cluster 20 emerging tourist destinations. We aim to contribute to tourism research literature by analysing how the dynamic interactions between the main tourist and economic indicators ultimately affected the positioning of destinations since the turn of the century. Li et al. (2013) noted the importance of the economic dimension in determining destinations competitiveness. Song et al. (2012) pointed out that one of the limitations of most tourism studies is the omission of economic indicators and the lack of attention paid to economic return. To cover this deficit, we combine official tourism data with economic information at the macro level, and generate an indicator of economic performance of inbound tourism (total number of international tourist arrivals) at the destination level: the ratio of total expenditure per tourist. 
On the one hand, we use data from the Compendium of Tourism Statistics provided by the World Tourism Organization (UNWTO). Data include the annual number of international overnight visitors, total expenditure, total number of rooms, and the percentage of the occupancy rates from 2000 to 2010 . The country selection criterion is based on the number of international overnight visitors and the availability of secondary data for the sample period, under the constraint that all regions are represented. We use the UNWTO regional classification.

On the other hand, we incorporate economic information in the form of the Gross Domestic Product (GDP) provided by the World Bank. Finally, in order to capture the relationship between tourism and development beyond economic growth alone, we include the Human Development Index (HDI), which is a composite indicator obtained as the geometric mean of three indices. The HDI can be regarded as a summary measure of average achievement in three key dimensions of human development: the health dimension, assessed by life expectancy at birth; the education dimension, measured by mean of years of schooling for adults aged 25 years and more and expected years of schooling for children of school entering age, and the standard of living dimension, which is measured by the logarithm of the gross national income (GNI) per capita so as to reflect the diminishing importance of income with increasing GNI.

This research also differs from previous destination positioning studies in that we use annual percentage growth rates of the variables to avoid the issues derived from working with non-stationary time series (Oh, 2005; Lim \& McAleer, 2002). Several authors have pointed out the importance of working with growth rates instead of levels (Li et al., 2013), since most tourism variables are non-stationary due to its steady growth (Chu et al., 2014).

The proposed approach for positioning tourist destinations is based on a two-step methodology proposed by Claveria (2016). First, we rank the 45 tourist destinations regarding their average growth rates in all items over the sample period, indirectly introducing a dynamic perspective into the analysis. By assigning a numerical value to each destination corresponding to its position in the rankings, we then cluster the destinations by means of two dimensionality reduction techniques: Multidimensional Scaling (MDS) and Categorical Principal Component Analysis (CATPCA). Finally, we use perceptual maps to project the results and to position the destinations.

The remainder of the study is organized as follows. The next section provides a review of the existing literature. Section 3 describes the data set. In Section 4 we rank the destinations and present the results of the multivariate analysis. Finally, Section 5 concludes. 


\section{Literature review}

The factors conditioning the demand for tourism range from politics to economics. Wang (2009) stressed the importance of identifying the key factors affecting tourism demand in order to effectively understand changes and trends in the tourism market, and create competitive advantages for the tourism industry. Several authors have examined the effects of economic variables in both the hospitality industry (Lee \& Ha, 2012) and tourism development (Novak et al., 2011; Pranić et al., 2012).

The contribution of tourism to economic growth, as well as to destination competitiveness, has been extensively analysed in the tourism literature (Balaguer \& Cantavella-Jordá, 2002, Brida et al., 2016; Capó et al., 2007; Chou, 2013; Croes, 2011; Crouch \& Richie, 1999, 2006; Durbarry, 2004; Oh, 2005; Pérez-Rodríguez et al., 2015; Schubert \& Brida, 2009; Schubert et al., 2011; Seo et al., 2010; Torraleja, 2009). Recent literature highlighted the role of capital formation, arguing that the mechanism underlying tourism's welfare-promoting effect heavily relies on capital goods imports (Nowak et al., 2007; Cortés-Jiménez et al. 2011). Foreign direct investment, trade volume, and exchange rates have also proved to be linked to tourism (Santana-Gallego et al., 2010, 2011; Wong \& Tang, 2010).

Nevertheless, there are few studies addressing the interdependence between tourism and economic growth by means of multivariate analysis (Chandra \& Menezes, 2001). Multivariate methods can be classified into two major categories: dependency and interdependency techniques. While dependency procedures assume that a set of variables is explained by other variables, interdependency methods involve the simultaneous analysis of all the variables in the dataset. By reducing the dimensionality in a dataset, interdependency analysis is used to detect underlying relationships between variables. There are several multivariate techniques for dimensionality reduction: cluster analysis, multiple correspondence analysis (MCA), exploratory factor analysis (EFA), confirmatory factor analysis (CFA), principal components (PCA), etc. For a detailed description of these techniques see Hair et al. (2009), Jolliffe (2002) and Sharma (1996).

Dimensionality reduction techniques have been used in a wide range of tourism studies: from image and perception analyses to motivation research. One of the main areas in which multivariate analysis is widely used is market segmentation studies (Dey \& Sarma, 2010; Donaire et al, 2014; Keng \& Cheng, 1999; Lee et al., 2006; Park \& Yoon, 2009; Rid et al., 2014; Sinclari-Maragh et al., 2015; Upchurch et al., 2004; Voges, 2007). 
Guo et al. (2015) conducted conjoint and a cluster analyses to segment Chinese spa customers in Hong Kong. Arimond \& Elfessi (2001) used MCA to spatially map attributes from a categorical survey data, and then cluster analysis to identify market segments.

MDS is also known as Principal Coordinates Analysis or Torgerson scaling (Torgerson, 1952, 1958). MDS is a multivariate analytical procedure that allows to visualize the level of similarity between individuals based on the proximity of individuals to each other in a generated projection, known as perceptual map. These representations allow the visualization of the strengths and weaknesses of destinations. For an overview of MDS, see Borg \& Groenen (2005), Borg et al. (2013) and Fentom \& Pearce (1988). In a recent study, Marcussen (2014) reviewed 64 papers that applied MDS to tourism research, finding that the most common topics were image and positioning of destinations. For a review of the literature on destination image see Pike (2002).

The first application of MDS to tourism destinations was that of Wish et al. (1970). Since then, a large number of studies have analysed the positioning of destinations by means of MDS (Andreu et al. 2000; Crompton et al., 1992; Gursoy et al., 2009; Kayar \& Kozak, 2010; Kim, 1998; Leung \& Baloglu, 2013; Li et al., 2015; Marcussen, 2014; Uysal et al., 2000). Haahti (1986) assessed the relative status of Finland as a summer holiday destination compared to nine European competitors. Applying a two-dimensional MDS analysis, Gartner (1989) clustered four American states with similar tourism and recreation attributes. Kim \& Agrusa (2005) positioned seven honeymoon destinations according to the perception of Korean tourists regarding eight attributes. Kim et al. (2005) used MDS to identify the position of overseas golf tourism destinations. Omerzel (2006) analysed the competitiveness of Slovenia as a tourist destination regarding the ratings for 85 indicators grouped into six categories. Via MDS analysis, Zins (2010) depicted destination images of ten different countries from the perspective of two traveller segments.

Lozano \& Gutierrez (2011) applied MDS to analyse 25 European destinations. Marcussen (2011) combined MDS with FA to position and group 33 European destinations in relation to each other. Using official data from Eurostat regarding monthly overnight stays from 1998 to 2009, the author found that European destinations could be grouped by major language spheres. Claveria \& Poluzzi (2017) arrived to a similar conclusion for the world's top ten destinations. 
In a similar study, Leung \& Baloglu (2013) evaluated the destination competitiveness of 16 Asia Pacific destinations, generating three-dimensional perceptual maps, and using cluster analysis to identify groupings on the maps. Recently, Li et al. (2015) analysed the position of the United States (US) against its major non-Asian competitors. By combining MDS, MCA, and logistic regression, the authors found that the US holds a unique position in relation to its competitor destinations. MDS has also been applied in other tourism studies. Chhetri et al. (2004) identified the underlying dimensions influencing visitor experiences in nature-based tourism destinations.

Recent developments in multivariate analysis focus on dealing with nonlinear relationships in data. PCA has been extended by using autoassociative neural networks (Kramer, 1991), principal curves and manifolds (Hastie \& Stuetzle, 1989), and kernel approaches (Schölkopf et al., 1998). Another machine learning technique are SelfOrganizing Maps (SOMs) (Kohonen, 2001). SOMs can be regarded as a nonlinear generalization of PCA (Liu \& Weisberg, 2005). SOM analysis is used to generate visual representations of data that allow to disclose unknown patterns. While SOMs are starting to be used in economic studies (Claveria et al., 2016; Sarlin \& Peltonen, 2013, ZarateSolano \& Zapata-Sanabria, 2017), to our knowledge, the only application in tourism is that of Bloom (2005), who used a SOM for segmenting the inbound tourism demand to Cape Town.

CATPCA, also known as nonlinear PCA, represents another development in nonlinear dimensionality reduction. See Gifi (1990) for a historical overview, and Linting et al. (2007) for an exhaustive treatment of nonlinear PCA. CATPCA does not assume that the relationships between variables are linear, and can discover nonlinear relationships between variables. Another advantage of CATPCA over standard PCA, is that it allows incorporating nominal and ordinal variables. In spite of these features, few studies have applied CATPCA in tourism research (Correia et al., 2007; Green, 2005).

In order to cover this deficit, we compare the performance of CATPCA and MDS in the positioning of the main 45 destinations based on the rankings regarding different official indicators that combine tourist and economic information. These procedures are used to reduce the dimensionality of data by transforming the original set of correlated variables into a smaller set of uncorrelated variables known as factors, which can be interpreted as synthetic indicators that maintain the original ordinal structures. 


\section{Data}

The dataset is comprised of two major sources of information: tourist and economic indicators. On the one hand, we use official data from the Compendium of Tourism Statistics provided by the UNWTO (http://www2.unwto.org/content/data-0). We focus on five indicators: overnight visitors (thousands), total expenditure (US\$ millions), occupancy rate (\%), rooms, and inbound expenditure over GDP (\%). From these set of data, we calculate and additional indicator of economic performance at the destination level: the ratio of total expenditure per tourist.

On the other hand, we add economic information in the form of the GDP at market prices based on constant local currency provided by the World Bank (http://data.worldbank.org/indicator/NY.GDP.MKTP.KD.ZG). Finally, we include the HDI (http://hdr.undp.org/en/content/human-development-index-hdi), which is a composite indicator of life expectancy, education, and income per capita that allows us to capture the relationship between tourism and development beyond a strictly economic sense.

The country selection criterion is based on the number of international overnight visitors and the availability of secondary data for the sample period (2000-2010), under the constraint that all regions are represented. We use the UNWTO regional classification, which divides the world into five major regions Europe (Northern, Western, Central/Eastern, Southern/Mediterranean), Asia and the Pacific (North-East Asia, SouthEast Asia, Oceania, South Asia), Americas (Caribbean, North, Central and South America), Africa (North, Sub-Saharan), and Middle East.

The set of countries is as follows (Table 1): Austria (1), Botswana (2), Bulgaria (3), Cambodia (4), Chile (5), China (6), Costa Rica (7), Croatia (8), Cyprus (9), Dominican Republic (10), Egypt (11), Estonia (12), Finland (13), France (14), Germany (15), Greece (16), Hong Kong (17), Indonesia (18), Ireland (19), Israel (20), Italy (21), Jamaica (22), Jordan (23), Latvia (24), Lithuania (25), Madagascar (26), Mexico (27), Morocco (28), New Zealand (29), Norway (30), Panama (31), Paraguay (32), Philippines (33), Poland (34), Portugal (35), Singapore (36), Slovenia (37), South Africa (38), Spain (39), Sri Lanka (40), Sweden (41), Tunisia (42), Turkey (43), United Kingdom (UK) (44), and the US (45).

The information in Table 1 indicates that the tourism sector is highly concentrated in few destinations, as the first five national markets (France, Spain, the US, China and Italy) 
account for almost $50 \%$ of world tourism. The next ten destinations (the UK, Germany, Mexico, Turkey, Austria, Greece, Poland, Hong Kong, Portugal and Egypt) represent an additional $32 \%$ of total international overnight visitors.

Table 1. Frequency distribution of international inbound tourism - Annual average 2000-2010

\begin{tabular}{|c|c|c|c|c|c|}
\hline Destination & $\begin{array}{c}\text { Average } \\
2000-2010\end{array}$ & $\begin{array}{l}\text { Relative } \\
\text { frequency } \\
\text { worldwide }\end{array}$ & Destination & $\begin{array}{c}\text { Average } \\
2000-2010\end{array}$ & $\begin{array}{l}\text { Relative } \\
\text { frequency } \\
\text { worldwide }\end{array}$ \\
\hline France & 76,934 & $14.43 \%$ & Sweden & 4,561 & $0.86 \%$ \\
\hline Spain & 53,019 & $9.94 \%$ & Norway & 3,811 & $0.71 \%$ \\
\hline US & 50,719 & $9.51 \%$ & Dom. Rep. & 3,558 & $0.67 \%$ \\
\hline China & 44,269 & $8.30 \%$ & Finland & 3,142 & $0.59 \%$ \\
\hline Italy & 40,731 & $7.64 \%$ & Jordan & 2,928 & $0.55 \%$ \\
\hline UK & 26,470 & $4.96 \%$ & Philippines & 2,559 & $0.48 \%$ \\
\hline Germany & 21,711 & $4.07 \%$ & Cyprus & 2,405 & $0.45 \%$ \\
\hline Mexico & 21,167 & $3.97 \%$ & New Zealand & 2,225 & $0.42 \%$ \\
\hline Turkey & 19,998 & $3.75 \%$ & Chile & 2,121 & $0.40 \%$ \\
\hline Austria & 19,956 & $3.74 \%$ & Israel & 1,867 & $0.35 \%$ \\
\hline Greece & 14,677 & $2.75 \%$ & Estonia & 1,762 & $0.33 \%$ \\
\hline Poland & 14,323 & $2.69 \%$ & Costa Rica & 1,593 & $0.30 \%$ \\
\hline Hong Kong & 13,981 & $2.62 \%$ & Botswana & 1,590 & $0.30 \%$ \\
\hline Portugal & 9,736 & $1.83 \%$ & Lithuania & 1,563 & $0.29 \%$ \\
\hline Egypt & 8,516 & $1.60 \%$ & Slovenia & 1,551 & $0.29 \%$ \\
\hline Croatia & 7,764 & $1.46 \%$ & Jamaica & 1,546 & $0.29 \%$ \\
\hline South Africa & 7,346 & $1.38 \%$ & Cambodia & 1,413 & $0.27 \%$ \\
\hline Ireland & 7,201 & $1.35 \%$ & Latvia & 1,153 & $0.22 \%$ \\
\hline Singapore & 6,916 & $1.30 \%$ & Panama & 831 & $0.16 \%$ \\
\hline Morocco & 6,242 & $1.17 \%$ & Sri Lanka & 485 & $0.09 \%$ \\
\hline Tunisia & 6,106 & $1.14 \%$ & Paraguay & 352 & $0.07 \%$ \\
\hline Indonesia & 5,453 & $1.02 \%$ & Madagascar & 221 & $0.04 \%$ \\
\hline Bulgaria & 4,618 & $0.87 \%$ & & & \\
\hline
\end{tabular}

Note: Tourist arrivals are measured in thousands. Dom. Rep. stands for the Dominican Republic.

In Table 2 we compute the annual percentage growth rates of all the variables used in the study. Given that growth rates are dimensionless measures of the amount of variation of a specific variable from one year to another in percentage terms, they provide a comparative overview of the evolution of the different tourist and economic indicators. Thus, Cambodia and Madagascar are the destinations that show the highest average growth rates for most variables. In the case of the expenditure per tourist, Cambodia obtains the second lowest average rate, as opposed to Madagascar with the highest 
average rate. At the opposite end, Cyprus shows some of the lowest average growth rates for most tourist variables (total expenditure, occupancy, and GDP).

Table 2. Descriptive analysis - Average annual percentage growth rates (2000-2010)

\begin{tabular}{|c|c|c|c|c|c|c|c|c|}
\hline & $\begin{array}{c}\text { Expenditure } \\
\text { per tourist }\end{array}$ & $\begin{array}{l}\text { Overnight } \\
\text { visitors }\end{array}$ & $\begin{array}{c}\text { Total } \\
\text { expenditure }\end{array}$ & $\begin{array}{l}\text { Inbound } \\
\text { expenditure } \\
\text { per GDP }\end{array}$ & Rooms & Occupancy & GDP & HDI \\
\hline Austria & 3.14 & 2.14 & 5.41 & -0.37 & -0.05 & 0.86 & 1.69 & 0.51 \\
\hline Botswana & -2.45 & 9.35 & 4.69 & -6.45 & 11.46 & 2.46 & 4.00 & 0.77 \\
\hline Bulgaria & 4.00 & 8.63 & 13.10 & -0.10 & 8.83 & -0.21 & 4.27 & 0.77 \\
\hline Cambodia & -1.63 & 20.20 & 18.45 & 6.44 & 12.47 & 3.79 & 8.12 & 1.82 \\
\hline Chile & 1.61 & 5.45 & 6.59 & -3.39 & 4.26 & 0.07 & 3.92 & 0.68 \\
\hline China & 4.66 & 7.23 & 12.51 & -3.61 & 6.49 & 1.19 & 10.33 & 1.55 \\
\hline Costa Rica & -1.16 & 6.93 & 5.87 & -2.06 & 3.88 & 1.77 & 4.16 & 0.85 \\
\hline Croatia & 4.67 & 9.06 & 12.83 & 1.04 & -0.72 & 6.80 & 2.65 & 0.63 \\
\hline Cyprus & 2.46 & -0.85 & 1.52 & -6.48 & -0.20 & -0.11 & 3.26 & 0.50 \\
\hline Dom. Rep. & 0.81 & 4.28 & 5.12 & -1.70 & 2.78 & 0.12 & 5.01 & 0.85 \\
\hline Egypt & 0.14 & 11.69 & 11.63 & 3.64 & 8.43 & 0.99 & 4.90 & 1.08 \\
\hline Estonia & -1.19 & 9.02 & 7.13 & 3.72 & 12.63 & 0.11 & 4.19 & 0.65 \\
\hline Finland & 3.58 & 3.91 & 7.19 & 1.13 & 0.15 & -1.64 & 2.12 & 0.52 \\
\hline France & 3.44 & 0.59 & 4.01 & -1.36 & 0.43 & 0.21 & 1.47 & 0.44 \\
\hline Germany & 2.21 & 4.33 & 6.56 & 2.23 & 0.73 & 1.03 & 1.12 & 0.53 \\
\hline Greece & 1.91 & 2.07 & 3.78 & -3.06 & 2.36 & -2.39 & 2.04 & 0.67 \\
\hline Hong Kong & 3.56 & 9.66 & 13.40 & 9.75 & 5.37 & 1.41 & 4.45 & 1.00 \\
\hline Indonesia & 2.41 & 4.02 & 7.00 & -6.78 & 3.28 & 1.35 & 5.21 & 1.39 \\
\hline Ireland & 7.51 & 1.13 & 8.84 & 1.13 & 1.97 & -1.13 & 3.18 & 0.42 \\
\hline Israel & 0.86 & 5.64 & 3.56 & -4.05 & 1.53 & -0.35 & 3.88 & 0.34 \\
\hline Italy & 1.76 & 1.80 & 3.20 & -1.95 & 1.25 & -0.74 & 0.64 & 0.56 \\
\hline Jamaica & -0.73 & 4.09 & 3.37 & -0.44 & 2.34 & 0.59 & -0.50 & 0.69 \\
\hline Jordan & 6.16 & 8.82 & 15.49 & 3.04 & 3.40 & 4.11 & 6.14 & 0.72 \\
\hline Latvia & 10.02 & 10.15 & 19.85 & 6.53 & 6.63 & -0.82 & 4.42 & 0.72 \\
\hline Lithuania & 6.35 & 2.12 & 6.72 & -5.07 & 7.08 & 1.99 & 1.59 & 0.87 \\
\hline
\end{tabular}

Notes: HDI stands for the annual average growth rate of the Human Development Indicator during 2000-2010. Statistics are conducted for the sample period: 2000-2010. Dom. Rep. stands for the Dominican Republic. 
Table 2. (cont.) Descriptive analysis - Average annual percentage growth rates (2000-2010)

\begin{tabular}{|c|c|c|c|c|c|c|c|c|}
\hline & $\begin{array}{c}\text { Expenditure } \\
\text { per tourist }\end{array}$ & $\begin{array}{l}\text { Overnight } \\
\text { visitors }\end{array}$ & $\begin{array}{c}\text { Total } \\
\text { expenditure }\end{array}$ & $\begin{array}{l}\text { Inbound } \\
\text { expenditure } \\
\text { per GDP }\end{array}$ & Rooms & Occupancy & GDP & HDI \\
\hline Madagascar & 18.43 & 14.93 & 18.72 & 12.91 & 8.49 & 5.19 & 2.94 & 1.24 \\
\hline Mexico & 2.37 & 1.98 & 4.37 & -2.65 & 3.33 & -0.15 & 2.14 & 0.64 \\
\hline Morocco & 4.63 & 8.50 & 13.40 & 5.17 & 5.50 & -2.99 & 4.64 & 1.35 \\
\hline New Zealand & 4.16 & 4.00 & 8.40 & -0.59 & 19.99 & 0.00 & 2.57 & 0.33 \\
\hline Norway & 2.82 & 3.72 & 6.80 & -2.59 & 1.89 & -0.93 & 1.72 & 0.32 \\
\hline Panama & 5.30 & 10.48 & 16.17 & 7.36 & 3.89 & 4.59 & 5.82 & 0.62 \\
\hline Paraguay & 5.32 & 5.35 & 10.74 & 1.16 & 5.21 & 0.83 & 3.01 & 0.79 \\
\hline Philippines & -0.36 & 4.93 & 5.16 & -4.02 & -5.86 & 1.37 & 4.74 & 0.61 \\
\hline Poland & 8.97 & -3.02 & 5.72 & -4.34 & 6.62 & -0.52 & 3.88 & 0.49 \\
\hline Portugal & 15.44 & -3.83 & 7.61 & 1.76 & 2.47 & -1.50 & 1.03 & 0.43 \\
\hline Singapore & 5.53 & 5.53 & 11.56 & 0.48 & 2.87 & 1.74 & 6.18 & 0.77 \\
\hline Slovenia & 2.66 & 7.28 & 9.85 & 2.47 & 3.23 & 1.09 & 2.86 & 0.58 \\
\hline South Africa & 9.59 & 3.59 & 12.53 & 0.97 & 2.86 & -0.57 & 3.55 & 0.78 \\
\hline Spain & 4.14 & 1.43 & 5.66 & -2.16 & 2.52 & -1.27 & 2.52 & 0.43 \\
\hline Sri Lanka & 5.87 & 5.20 & 10.92 & -0.33 & 2.62 & 3.38 & 5.27 & -0.01 \\
\hline Sweden & 2.93 & 6.89 & 8.25 & 3.53 & 1.44 & 0.73 & 2.39 & 0.11 \\
\hline Tunisia & 1.52 & 3.45 & 5.20 & -1.98 & 2.12 & -0.63 & 4.45 & 1.01 \\
\hline Turkey & -0.04 & 15.61 & 15.28 & 8.31 & 6.22 & 2.74 & 4.26 & 1.04 \\
\hline UK & 0.97 & 1.98 & 3.14 & -0.42 & 2.40 & 0.71 & 1.94 & 0.39 \\
\hline US & 1.74 & 2.16 & 4.03 & 0.01 & 1.93 & -0.75 & 1.88 & 0.29 \\
\hline
\end{tabular}

Notes: $\quad$ See Notes of Table 2

\section{Multivariate analysis}

\subsection{Ranking of destinations}

In this section we rank the 45 destinations according to the average annual growth experienced over the period comprised from 2000 to 2010 for each variable (Table 3). 
Table 3. Ranking of destinations - Average annual percentage growth rates (2000-2010)

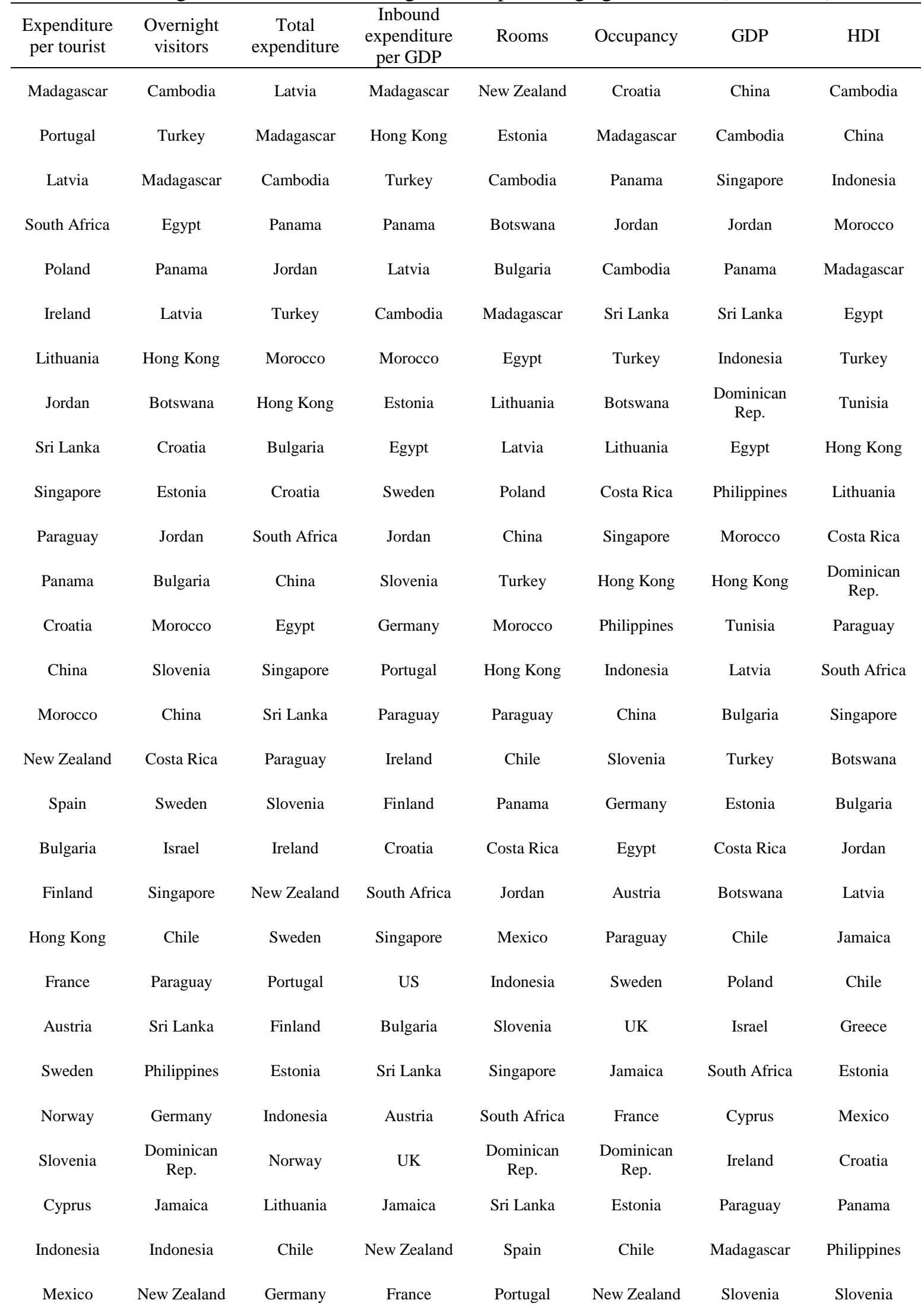

Notes: HDI stands for the annual average growth rate of the Human Development Indicator. Dom. Rep. stands for the Dominican Republic. 


\begin{tabular}{|c|c|c|c|c|c|c|c|}
\hline $\begin{array}{l}\text { Expenditure } \\
\text { per tourist }\end{array}$ & $\begin{array}{c}\text { Overnight } \\
\text { visitors }\end{array}$ & $\begin{array}{c}\text { Total } \\
\text { expenditure }\end{array}$ & $\begin{array}{l}\text { Inbound } \\
\text { expenditure } \\
\text { per GDP }\end{array}$ & Rooms & Occupancy & GDP & HDI \\
\hline Germany & Finland & Costa Rica & $\begin{array}{l}\text { Dominican } \\
\text { Rep. }\end{array}$ & UK & Cyprus & Croatia & Italy \\
\hline Greece & Norway & Poland & Italy & Greece & Mexico & New Zealand & Germany \\
\hline Italy & South Africa & Spain & Tunisia & Jamaica & Bulgaria & Spain & Finland \\
\hline US & Tunisia & Austria & Costa Rica & Tunisia & Israel & Sweden & Austria \\
\hline Chile & US & Tunisia & Spain & Ireland & Poland & Mexico & Cyprus \\
\hline Tunisia & Austria & Philippines & Norway & US & South Africa & Finland & Poland \\
\hline UK & Lithuania & $\begin{array}{l}\text { Dominican } \\
\text { Rep. }\end{array}$ & Mexico & Norway & Tunisia & Greece & France \\
\hline Israel & Greece & Botswana & Greece & Israel & Italy & UK & Spain \\
\hline $\begin{array}{l}\text { Dominican } \\
\text { Rep. }\end{array}$ & UK & Mexico & Chile & Sweden & US & US & Portugal \\
\hline Egypt & Mexico & US & China & Italy & Latvia & Norway & Ireland \\
\hline Turkey & Italy & France & Philippines & Germany & Norway & Austria & UK \\
\hline Philippines & Spain & Greece & Israel & France & Ireland & Lithuania & Israel \\
\hline Jamaica & Ireland & Israel & Poland & Finland & Spain & France & New Zealand \\
\hline Costa Rica & France & Jamaica & Lithuania & Austria & Portugal & Germany & Norway \\
\hline Estonia & Cyprus & Italy & Botswana & Cyprus & Finland & Portugal & US \\
\hline Cambodia & Poland & UK & Cyprus & Croatia & Greece & Italy & Sweden \\
\hline Botswana & Portugal & Cyprus & Indonesia & Philippines & Morocco & Jamaica & Sri Lanka \\
\hline
\end{tabular}

Notes: See Note of Table 3.

The rankings in Table 3 confirm some of the results of the previous section. China and Cambodia are in the top positions regarding the average growth in GDP and HDI. Cambodia is also in the top positions in all tourist indicators except for the average growth rate in expenditure per tourist. Madagascar is in the first position with respect to the average growth of the expenditure per tourist and the inbound expenditure over GDP, and in the top positions for most of the indicators with the exception of GDP. On the other extreme, Cyprus occupies low positions in most tourist indicators. See Sun et al. (2015), Chheang (2008), Peypoch et al. (2012) and Altinay \& Bowen (2006) for recent tourism research about China, Cambodia, Madagascar and Cyprus respectively. 


\subsection{Positioning of destinations}

By assigning a numerical value to each country corresponding to its ranking in Table 3 , we generate a set of categorical data that we use to cluster the different destinations. The grouping of all countries is done by means of two optimal scaling techniques for categorical data: CATPCA and MDS, using IBM SPSS Statistics 24 (Meulman et al., 2012).

Both techniques allow us to reduce the information contained in Table 3 into two dimensions. We have used the Kaiser-Guttman method (Guttman, 1954; Kaiser, 1960; Yeomans \& Golder, 1982) in order to determine the number of factors to retain. According to this criterion, only the factors that have eigenvalues greater than one are retained for interpretation. Eigenvalues represent the amount of variance accounted for by a specific component. Each component has an eigenvalue, so the sum of all eigenvalues equals the number of variables in a component analysis. In the screeplot of Fig. 1 we graph the eigenvalues of the correlation matrix of the quantified variables. We can observe that only the first two factors have eigenvalues larger than the unity. As a result, the appropriate number of components to be chosen is two.

In Table 4 we present a summary of the models. Regarding CATPCA, the first two factors account for almost $83 \%$ of the variance of the variables under analysis, indicating a similar goodness of fit of the components as the obtained with the MDS model.

Table 5 shows the obtained component loadings, which we use to label the two dimensions to which we have reduced the dataset to. We have applied Varimax rotation to facilitate the interpretation of the components. The five factors with the highest loadings in the first dimension are (Fig. 2): the rakings regarding the average growth of overnight visitors, total expenditure, rooms, GDP and HDI. Therefore, the first dimension better captures the aspects reflecting the development of the economy and the tourism industry, whereas the second dimension those more related to the profitability of the tourist activity at the destination level. Accordingly, we label the first dimension as "tourist and economic development", and the second as "economic performance of tourist activity". 
Fig. 1. Scree plot

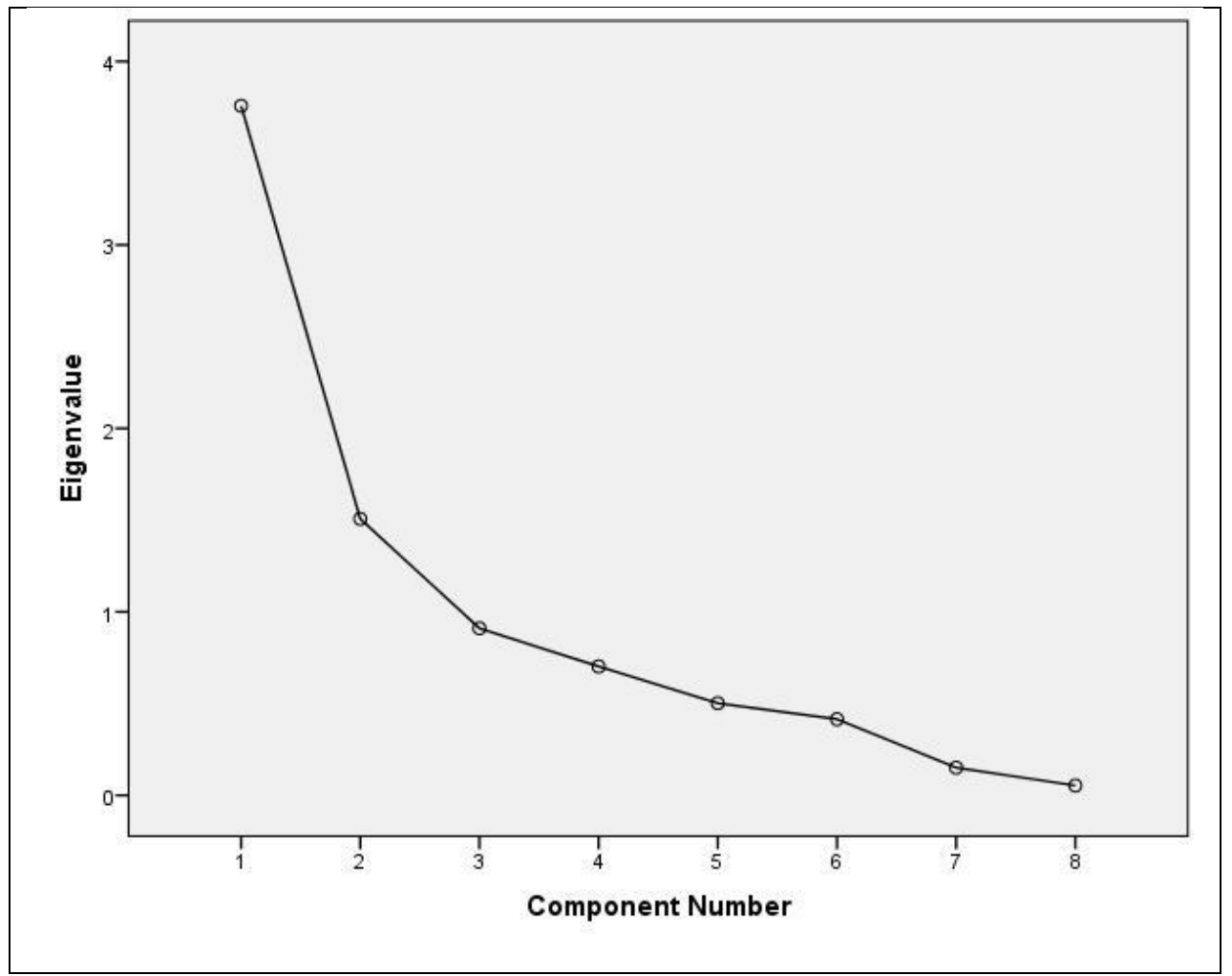

Table 4. Multivariate analysis - Summary

\begin{tabular}{|c|c|c|c|c|c|}
\hline \multicolumn{4}{|c|}{ CATPCA Model } & \multicolumn{2}{|c|}{ MDS Model } \\
\hline \multirow[b]{2}{*}{ Dimension } & \multirow{2}{*}{$\begin{array}{l}\text { Cronbach's } \\
\text { alpha }\end{array}$} & \multicolumn{2}{|c|}{ Variance } & \multirow[b]{2}{*}{ Stress } & \multirow[b]{2}{*}{0.17} \\
\hline & & $\begin{array}{c}\text { Total } \\
\text { (eigenvalue) }\end{array}$ & $\begin{array}{c}\% \text { of } \\
\text { variance }\end{array}$ & & \\
\hline 1 & 0.85 & 3.65 & 45.62 & \multirow{3}{*}{ RSQ } & \multirow{3}{*}{0.86} \\
\hline 2 & 0.79 & 2.98 & 37.24 & & \\
\hline Total & 0.97 & 6.63 & 82.87 & & \\
\hline
\end{tabular}

Notes: *Cronbach's alpha mean is based on the mean of the eigenvalue. Rotation method: Varimax with Kaiser Normalisation. Kruskal's stress values indicate the amount of distortion in distances to tolerate. Stress values range from zero to one, zero indicating a perfect representation of the input data in two dimensions. The RSQ stands for the squared correlations in distances. RSQ values are the proportion of variance of the scaled data (disparities) in the partition which is accounted for by their corresponding distances. 
Table 5. Rotated component loadings - CATPCA

\begin{tabular}{l|cc}
\hline \multirow{2}{*}{\multicolumn{1}{c|}{ Position }} & \multicolumn{2}{c}{ Dimension } \\
\cline { 2 - 3 } Expenditure per tourist & $\mathbf{1}$ & $\mathbf{2}$ \\
Overnight visitors & .055 & .949 \\
Total expenditure & .854 & .359 \\
Inbound expenditure per GDP & .765 & .518 \\
Rooms & .206 & .942 \\
Occupancy & .805 & .097 \\
GDP & .029 & .860 \\
HDI & .898 & -.198 \\
Note: $\quad \begin{array}{l}\text { Rotation method: Varimax with Kaiser Normalisation. Component } \\
\text { loadings indicate Pearson correlations between the quantified }\end{array}$ \\
\multicolumn{2}{l}{ variables and the principal components (ranging between -1 and 1). }
\end{tabular}

Fig. 2. Variance accounted for the first two dimensions

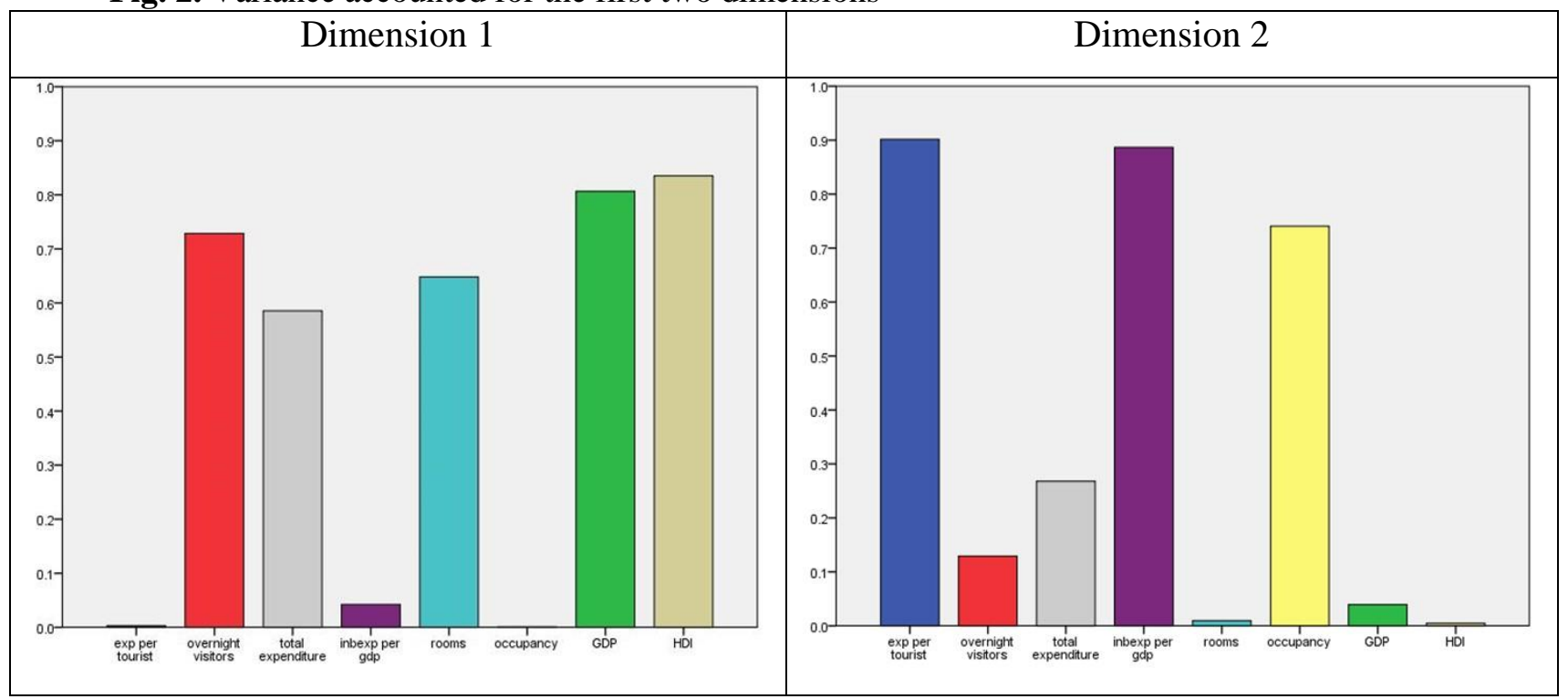

Figures 3 and 4 are two-dimensional scatterplots that represent the coordinates of the first two retained dimensions for each destination. Fig. 3 shows the biplot projecting the two dimensions obtained with CATPCA, and Fig. 4 the perceptual map projecting the first two dimensions obtained by means of MDS. Along both dimensions, the biplot in Fig. 3 overlaps the object scores (destinations) and the component loadings (indicators). The coordinates of the end point of each vector are given by the loadings of each variable on the two components. Long vectors are indicative of a good fit. The variables that are close together in the plot are positively related, while the variables with vectors that make approximately a $180^{\circ}$ angle with each other are closely and negatively related. Finally, variables that are not related correspond with vectors making a $90^{\circ}$ angle. 
In Fig. 3 we can observe that the first dimension captures more variance than the second dimension, both among the items and the cases. The rankings regarding expenditure per tourist, expenditure over GDP and occupancy tend to coalesce together, indicating a close and positive relation between them, but no relation with the rest of the variables. The rankings regarding total expenditure and overnight visitors also coalesce together, in a similar way as the rankings regarding the growth in rooms and HDI, and GDP to a lesser extent.

Fig. 3. Biplot with rotated component loadings and objects - CATPCA

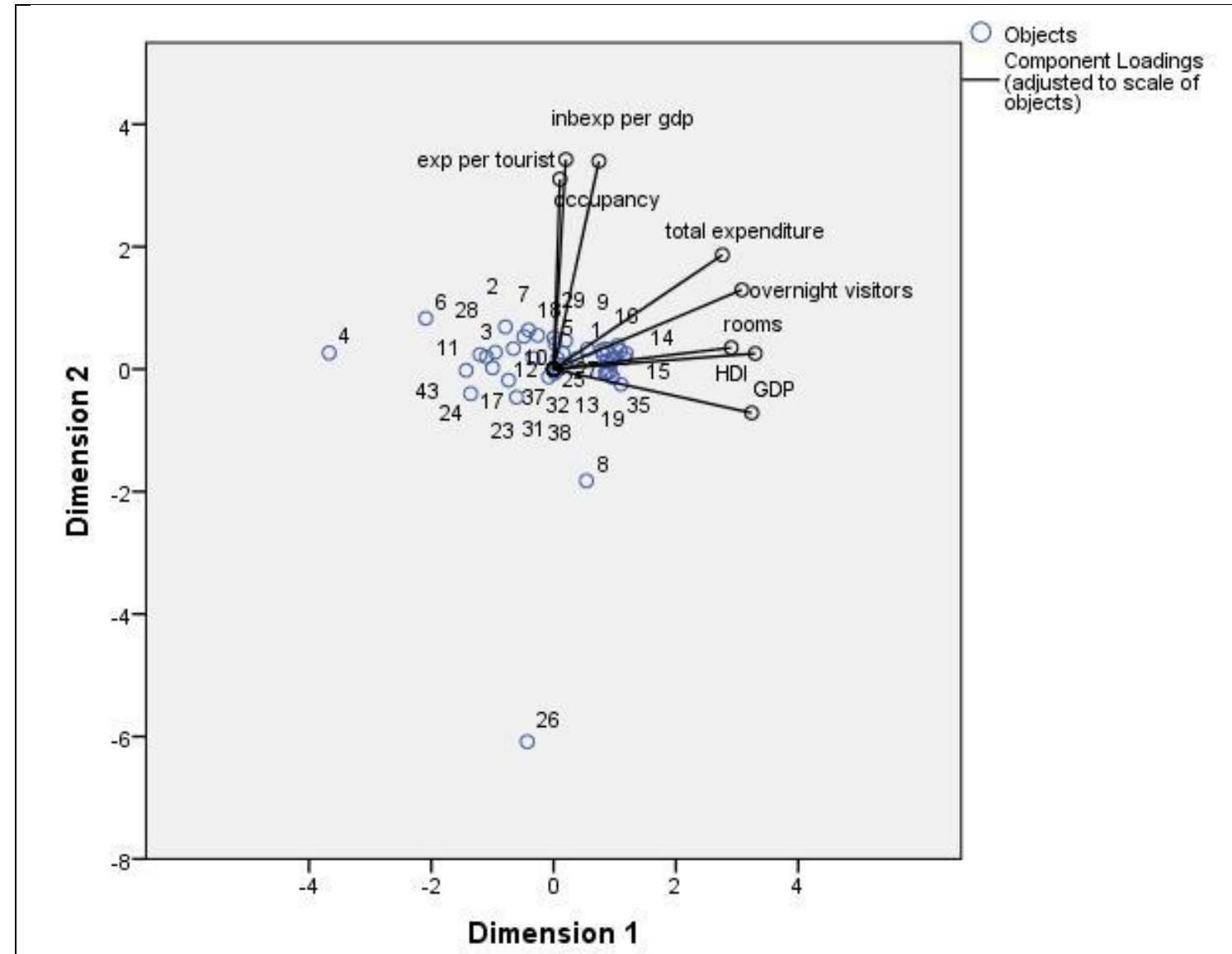

Note: Rotation method: Varimax with Kaiser Normalisation. For visual clarity, we have coded each country with a number: Austria (1), Botswana (2), Bulgaria (3), Cambodia (4), Chile (5), China (6), Costa Rica (7), Croatia (8), Cyprus (9), Dominican Republic (10), Egypt (11), Estonia (12), Finland (13), France (14), Germany (15), Greece (16), Hong Kong (17), Indonesia (18), Ireland (19), Israel (20), Italy (21), Jamaica (22), Jordan (23), Latvia (24), Lithuania (25), Madagascar (26), Mexico (27), Morocco (28), New Zealand (29), Norway (30), Panama (31), Paraguay (32), Philippines (33), Poland (34), Portugal (35), Singapore (36), Slovenia (37), South Africa (38), Spain (39), Sri Lanka (40), Sweden (41), Tunisia (42), Turkey (43), UK (44), and the US (45). 
Fig. 4. Perceptual map - MDS

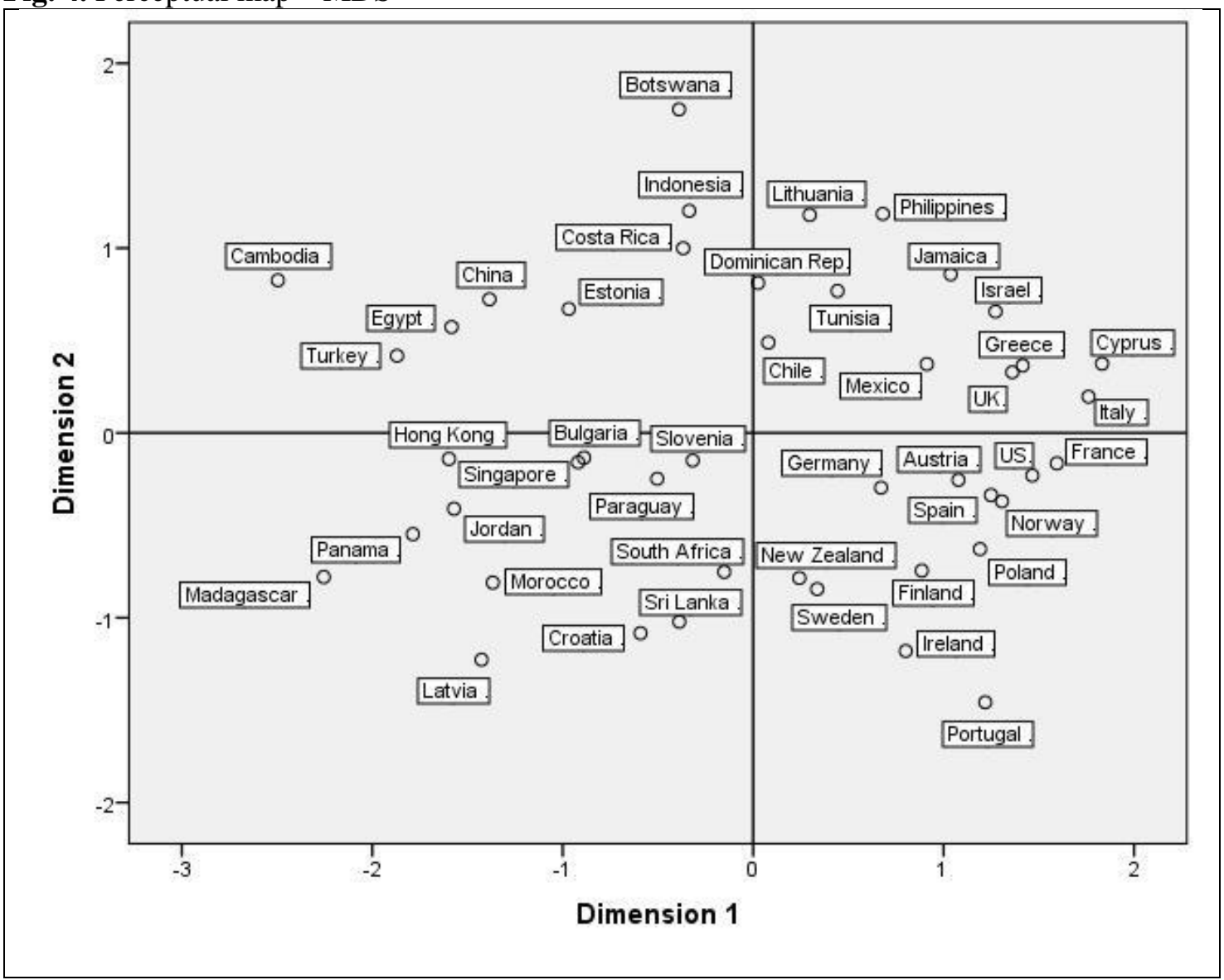

Note: Derived stimulus configuration. Euclidean distance model.

The perceptual map in Fig. 4 is divided in four quadrants. The first top right quadrant contains destinations with high scores in both dimensions: Lithuania, the Philippines, Jamaica, Dominican Republic, Chile, Mexico, Tunisia, Israel, Greece, Cyprus, Italy, and the UK. In the lower right quadrant, with high scores in the first dimension, we find France, Germany, Austria, Spain, Portugal, Ireland, Poland, Sweden, Finland, Norway and New Zealand. In the next quadrant to the left, we have Panama, Hong Kong, Singapore, Sri Lanka, Madagascar, South Africa, Morocco, Jordan, Bulgaria, Croatia, Slovenia and Latvia. Finally, the last quadrant, contains the countries with high scores in the second dimension: China, Cambodia, Indonesia, Botswana, Costa Rica, Estonia, Turkey and Egypt.

To a certain extent, the first quadrant is dominated by Mediterranean destinations (Cyprus, Greece, Israel, Italy), while in the second there is a predominance of Western and Northern Europe destinations, containing some of the most of mature markets (Austria, France, the US). In the third group, we find a high proportion of Eastern Europe destinations (Bulgaria, Croatia and Latvia), and Madagascar, slightly apart from the rest. A similar thing happens with Cambodia in the fourth quadrant top left. This differentiated 
positioning is due to the fact that both countries experienced the highest average growth rates for most variables during the sample period, displaying top positions in most tourist indicators (Table 3). However, while Madagascar is in the first position with respect to the average growth of the expenditure per tourist, Cambodia has the second lowest average rate. This persistent growth of the tourism industry in Cambodia poses profound challenges, especially in terms of profitability. Chens et al. (2008) found that in spite of Cambodia's endowed resources, the country needed supporting factors to increase its competitiveness.

On the whole, both techniques depict a similar positioning of the destinations with respect of the rankings in Table 3. The groupings are also consistent with the results of the descriptive analysis in Section 3. These results show the potential of dimensionality reduction and data visualization techniques for exploratory data analysis, as well as their applicability as tools for the identification of key attributes in the positioning of tourism destinations.

This evidence adds to previous studies by Assaf \& Tsionas (2015), Claveria (2016, 2017), Huang \& Peng (2012), and Yau \& Chan (1990). Yau \& Chan (1990) used MDS to map seven cities of the Asia and the Pacific region regarding prices and range of activities, and they also found that the market position of Singapore was close to that of Hong Kong. Assaf \& Tsionas (2015) ranked 101 countries according to 20 indicators of quality grouped in three dimensions (infrastructure, human resources and nature), finding that based on overall quality, Cambodia, Egypt and Madagascar were worse positioned than the rest of the destinations analysed in the study. In their research, most of the countries with low scores in infrastructure fell below the median, while Austria, the US, the UK, France, New Zealand and Sweden were in the top positions.

\section{Summary and concluding remarks}

This study assesses the performance of data visualization techniques for the positioning of tourism destinations. We compare the performance of CATPCA and MDS. These techniques allow us to generate two-dimensional visual representations of large datasets. Via perceptual maps we capture the strengths and weaknesses of destinations, and allow visualizing the similarity between them.

First, the world's 45 top destinations were ranked according to the average annual growth experienced over the sample period for a set of tourism and economic indicators. 
By means of two dimensionality reduction techniques for categorical data, all the information was summarised into two components: "tourist and economic development" and "economic performance of tourist activity". Finally, two-dimensional projections representing the coordinates of the first two retained dimensions for each country were generated to map all destinations simultaneously.

We found that countries can be clustered into four different groups. The first one, containing some of the destinations with the highest scores in both dimensions, is dominated by Mediterranean countries (Cyprus, Greece, Israel, and Italy). In the second group there is a predominance of Western and Northern Europe destinations, and it contains some of the most of mature markets (Austria, France, and the US). The third group, with low scores in the first dimension but high ones in the second, is the more geographic diverse, with countries like Cambodia, China, Botswana, Egypt and Turkey. Finally, in the group with low scores in both dimensions, we find a high proportion of Eastern Europe destinations (Bulgaria, Croatia and Latvia).

The study aims to shed some light on how the interactions between the main tourist and economic indicators ultimately affects the positioning of destinations. Given that the analysis exclusively makes use of official data, it is easily replicable to different sets of destinations. The proposed approach facilitates the identification of attributes that are most relevant in positioning tourism destinations, and could thereby assist in monitoring the evolution of destination competitiveness in an ever-changing tourism market, and in the enhancement of destinations competitiveness.

Nevertheless, this is is a descriptive study, and inference cannot be made. Either for lack of data, or the existence of outliers, there have been several issues left for further research. An independent analysis by purpose of travel and the inclusion of additional tourism indicators, such as the contribution of tourism to employment or the average expenditure per day, would give further insight into the profitability and the contribution of tourism development to economic growth. On the other hand, another question left for future research is the implementation and assessment of artificial intelligence techniques such as self-organizing maps in the positioning of the destinations.

\section{Acknowledgements}

We wish to thank Laura Muñoz and Jacinta García at the World Tourism Organization (UNWTO) for providing us with the data used in this study. This paper has been partially financed by the project ECO2016-75805-R of the Spanish Ministry of Economy and Competitiveness. 


\section{References}

Altinay, L., \& Bowen, D. (2006). Politics and tourism interface: The case of Cyprus. Annals of Tourism Research, 33(4), 939-956.

Andreu, L., Bigné, J. E., \& Cooper, C. (2000). Projected and perceived image of Spain as a tourist destination for British travellers. Journal of Travel and Tourism Marketing, 9(4), 47-67.

Arimond, G., \& Elfessi, A. (2001). A clustering method for categorical data in tourism market segmentation research. Journal of Travel Research, 39(4), 391-397.

Assaf, A. G., \& Tsionas, E. G. (2015). Incorporating destination quality into the measurement of tourism performance: A Bayesian approach. Tourism Management, 49, 58-71.

Balaguer, J., \& Cantavella-Jordá, M. (2002). Tourism as a long-run economic growth factor: The Spanish case. Applied Economics, 34(7), 877-884.

Bloom, J. Z. (2005). Market segmentation: A neural network application. Annals of Tourism Research, 32(1), 93-111.

Borg, I., \& Groenen, P. J. F. (2005). Modern multidimensional scaling: Theory and applications (2nd Ed.). New York: Springer-Verlag.

Borg, I., Groenen, P. J. F., Patrick, M. (2013). Applied multidimensional scaling. Berlin: Springer-Verlag.

Brida, J. G., Cortes-Jimenez, I., \& Pulina, M. (2016). Has the tourism-led growth hypothesis been validated? A literature review. Current Issues in Tourism, 19(5), 394-430.

Capó, J., Riera, A., \& Rosselló, J. (2007). Tourism and long-term growth. A Spanish perspective. Annals of Tourism Research, 34(3), 709-726.

Chandra, S., \& Menezes, D. (2001). Applications of multivariate analysis in international tourism research: The marketing strategy perspective of NTOs. Journal of Economic and Social Research, 3(1), 77-98.

Chens, C. Y., Sok, P., \& Sok, K. (2008). Evaluating the competitiveness of the tourism industry in Cambodia: Self-assessment from professionals. Asia Pacific Journal of Tourism Research, 13(1), 41-66.

Chheang, V. (2008). The political economy of tourism in Cambodia. Asia Pacific Journal of Tourism Research, 13(3), 281-297.

Chhetri, P., Arrowsmith, C., \& Jackson, M. (2004). Determining hiking experiences in nature-based tourism destinations. Tourism Management, 25(1), 31-43.

Chou, M. C. (2013). Does tourism development promote economic growth in transition countries? A panel data analysis. Economic Modelling, 33, 226-232.

Chu, H. P., Yeh, M. L., \& Chang, T. Y. (2014). Are visitor arrivals to China stationary? An empirical note. Asia Pacific Journal of Tourism Research, 19(2), 248-256.

Claveria, O. (2016). Positioning emerging tourism markets using tourism and economic indicators. Journal of Hospitality and Tourism Management, 29, 143-153.

Claveria, O. (2017). Two-dimensional mapping of Asia Pacific destinations combining tourism and economic indicators. Asia Pacific Journal of Tourism Research, 22(7), 720-734.

Claveria, O., Monte, E., \& Torra, S. (2016). A self-organizing map analysis of surveybased agents' expectations before impending shocks for model selection: The case of the 2008 financial crisis. International Economics, 146, 40-58. 
Claveria, O., \& Poluzzi, A. (2017). Positioning and clustering of the world's top tourist destinations by means of dimensionality reduction techniques for categorical data. Journal of Destination Marketing \& Management, 6(1), 22-32.

Cohen, S. A., Prayag, G., \& Moital, M. (2014). Consumer behaviour in tourism: Concepts, influences and opportunities. Current Issues in Tourism, 17(10), 872-909.

Correia, A., Oom do Valle, P., \& Moço, C. (2007). Modeling motivations and perceptions of Portuguese tourists. Journal of Business Research, 60(1), 76-80.

Cortes-Jimenez, I., Nowak, J., \& Sahli, M. (2011). Mass beach tourism and economic growth: Lessons from Tunisia. Tourism Economics, 17(3), 531-547.

Croes, R. (2011). Measuring and explaining competitiveness in the context of small island destinations. Journal of Travel Research, 50(4), 431-442.

Crompton, J. L., Fakeye, P. C., \& Lue, C. (1992). Positioning: The example of the Lower Rio Grande Valley in the winter long stay destination market. Journal of Travel Research, 31, 20-26.

Crouch, G. I., \& Ritchie, J. R. B. (1999). Tourism, competitiveness and social prosperity. Journal of Business Research, 44(3), 137-152.

Crouch, G., \& Ritchie, J. R. B. (2006). Competitiveness and tourism. In L. Dwyer \& P. Forsyth (Eds.), International Handbook on the Economics of Tourism (pp. 419-433). Cheltenham: Edward Elgar Publishing.

Dey, B., \& Sarma, M. K. (2010). Information source usage among motive-based segments of travellers to newly emerging tourist destinations. Tourism Management, 31(3), 341-344.

Donaire, J. A., Camprubí, R., \& Galí, N. (2014). Tourist clusters from Flickr travel photography. Tourism Management Perspectives, 11, 26-33.

Durbarry, R. (2004). Tourism and economic growth: the case of Mauritius. Tourism Economics, 10(4), 389-401.

Fentom, M., \& Pearce, P. (1988). Multidimensional scaling and tourism research. Annals of Tourism Research, 15, 236-254.

Gartner, W. C. (1989). Tourism image: Attribute measurement of state tourism products using multidimensional scaling techniques. Journal of Travel Research, 28, 16-20.

Gifi, A. (1990). Nonlinear multivariate analysis. Chichester, England: Wiley.

Green, R. (2005). Community perceptions of environmental and social change and tourism development on the island of Koh Samui, Thailand. Journal of Environmental Psychology, 25(1), 37-56.

Gursoy, D., Baloglu, S., \& Chi, C. G. (2009). Destination competitiveness of Middle Eastern countries: An examination of relative positioning. Anatolia, 20(1), 151-163.

Guttman, L. (1954). Some necessary and sufficient conditions for common factor analysis. Psychometrika, 19(2), 149-161.

Haahti, A. J. (1986). Finland's competitive position as a destination. Annals of Tourism Research, 13(1), 11-35.

Hair, J. F., Black, W. C., Babin, B. J., \& Anderson, R. E. (2009). Multivariate data analysis (7th Ed.). Upper Saddle River, NJ: Prentice Hall.

Hastie, T., \& Stuetzle, W. (1989). Principal curves. Journal of the American Statistical Association, 84 (406), 502-516.

Huang, J. H., \& Peng, K. H. (2012). Fuzzy Rasch model in TOPSIS: A new approach for generating fuzzy numbers to assess the competitiveness of the tourism industries in Asian countries. Tourism Management, 33(2), 456-465.

Jolliffe, I. T. (2002). Principal component analysis (2nd Ed.). Springer Series in Statistics.

Kaiser, H. F. (1960). The application of electronic computers to factor analysis. Educational and Psychological Measurement, 20, 141-151. 
Kayar, C. H., \& Kozak, N. (2010). Measuring destination competitiveness: An application of the Travel and Tourism Competitiveness Index (2007). Journal of Hospitality Marketing \& Management, 19(3), 203-216.

Keng, K. A., \& Cheng, J. L. (1999). Determining tourist role typologies: An exploratory study of Singapore vacationers. Journal of Travel Research, 37 (4): 382-390.

Kim, H. (1998). Perceived attractiveness of Korean destinations. Annals of Tourism Research, 25(2), 340-361.

Kim, S. S., \& Agrusa, J. (2005). The positioning of overseas honeymoon destinations. Annals of Tourism Research, 32(4), 887-904.

Kim, S. S., Chun, H., \& Petrick, J. F. (2005). Positioning analysis of overseas golf tour destinations by Korean golf tourists. Tourism Management, 26(6), 905-917.

Kohonen T. (2001). Self-organizing maps. Springer: Berlin.

Kramer, M. A. (1991). Nonlinear principal component analysis using autoassociative neural networks. AIChE Journal, 37(2), 233-243.

Lee, C. K., Lee, Y. K., Bernhard, B. J., \& Yoon, Y. S. (2006). Segmenting casino gamblers by motivation: A cluster analysis of Korean gamblers. Tourism Management, 27(5), 856-866.

Lee, K., \& Ha, I. S. (2012). Exploring the impacts of key economic indicators and economic recessions in the restaurant industry. Journal of Hospitality Marketing \& Management, 21 (3), 330-343.

Leung, X. Y., \& Baloglu, S. (2013). Tourism competitiveness of Asia Pacific destinations. Tourism Analysis, 18(4), 371-384.

Li, X. (Robert), Cheng, C., Kim, H., \& Li, X. (2015). Positioning USA in the Chinese outbound travel market. Journal of Hospitality \& Tourism Research, 39(1), 75-104.

Li, G., Song, H., Cao, Z., \& Wu, D. C. (2013). How competitive is Hong Kong against its competitors? An econometric study. Tourism Management, 36, 247-256.

Lim, C., \& McAleer, M. (2002). Time series forecasts of international travel demand for Australia. Tourism Management, 23(4), 389-396.

Linting, M., Meulman, J. J., Groenen, P. J. F., \& Van der Kooij, A. J. (2007). Nonlinear principal component analysis: Introduction and application. Psychological Methods, 12(3), 336-358.

Liu, Y., \& Weisberg, R. H. (2005). Patterns of ocean current variability on the west Florida shelf using the self-organizing map. Journal of Geophysical Research, 110(C6), 1-12.

Lozano, S., \& Gutiérrez, E. (2011). Efficiency analysis of EU-25 member states as tourist destinations. International Journal of Services Technology and Management, $15(1 / 2), 69-88$.

Maguigad, V. M. (2013). Tourism planning in archipelagic Philippines: A case review. Tourism Management Perspectives, 7, 25-33.

Marcussen, C. H. (2011). Visualising groups of European destinations. European Journal of Travel Research, 4(2), 180-190.

Marcussen, C. H. (2014). Multidimensional scaling in tourism literature. Tourism Management Perspectives, 12, 31-40.

Mariani, M. M., Buhalis, D., Longhi, C., \& Vitouladiti, O. (2014). Managing change in tourism destinations: Key issues and current trends. Journal of Destination Marketing \& Management, 2(4), 269-272.

Meng, X., Siriwardana, M., \& Pham, T. (2013). A CGE assessment of Singapore's tourism policies. Tourism Management, 34, 25-36.

Meulman, J. J., Heiser, W. J., \& SPSS. (2012). SPSS Categories 20.0. Chicago, Illinois: SPSS. 
Novak, M., Petrić, L., \& Pranić, L. (2011). The effects of selected macroeconomic variables on the presence of foreign hotels in Croatia. Tourism and Hospitality Management, 17 (1), 45-65.

Nowak, J., Sahli, M., \& Cortes-Jimenez, I. (2007). Tourism, capital goods imports and economic growth: theory and evidence for Spain. Tourism Economics, 13(4), 515536.

Oh, C. O. (2005). The contribution of tourism development to economic growth in the Korean economy. Tourism Management, 26(1), 39-44.

Omerzel, D. G. (2006). Competitiveness of Slovenia as a Tourist Destination. Managing Global Transitions, 4(2), 167-189.

Park, D. B., \& Yoon, Y. S. (2009). Segmentation by motivation in rural tourism: A Korean case study. Tourism Management, 30(1), 99-108.

Pérez-Rodríguez, J. V., Ledesma-Rodríguez, F., \& Santana-Gallego, M. (2015). Testing dependence between GDP and tourism's growth rates. Tourism Management, 48, 268-282.

Peypoch, N., Randriamboarison, R., Rasoamananjara, F., \& Solonandrasan, B. (2012). The length of stay of tourists in Madagascar. Tourism Management, 33(5), 12301235.

Pike, S. (2002). Destination image analysis - A review of 142 papers from 1973 to 2000. Tourism Management, 23(5), 541-549.

Pranić, L., Ketkar, S., \& Roehl, W. S. (2012). The impact of macroeconomic countryspecific factors on international expansion of US hotel chains. Tourismos, 7 (1), 155173.

Rid, W., Ezeuduji, I. O., \& Pröbstl-Haider, U. (2014). Segmentation by motivation for rural tourism activities in The Gambia. Tourism Management, 40, 102-116.

Santana-Gallego, M., Ledesma-Rodríguez, F. J., \& Pérez-Rodríguez, J. V. (2010). Exchange rate regimes and tourism. Tourism Economics, 16(1), 25-43.

Santana-Gallego, M., Ledesma-Rodriguez, F. J., \& Perez-Rodriguez, J. V. (2011). Tourism and trade in small island regions: The case of the Canary islands. Tourism Economics, 17(1), 107-125.

Sarlin, P., \& Peltonen, T. A. (2013). Mapping the state of financial stability. Journal of International Financial Markets, Institutions \& Money, 26, 46-76.

Schölkopf, B., Smola, A. J., \& Müller, K. (1988). Nonlinear component analysis as a kernel eigenvalue problem. Neural Computation, 10(5), 1299-1319.

Schubert, S. F., \& Brida, J. G. (2009). Macroeconomic effects of changes in tourism demand: A simple dynamic model. Tourism Economics, 15(3), 591-613.

Schubert, S. F., Brida, J. G., \& Risso, W. A. (2011). The impacts of international tourism demand on economic growth of small economies dependent on tourism. Tourism Management, 32, 377-385.

Seo, J. H., Park, S. Y., \& Boo, S. (2010). Interrelationships among Korean outbound tourism demand: Granger causality analysis. Tourism Economics, 16(3), 597-610.

Sharma, S. (1996). Applied multivariate techniques. New York: Wiley and Sons.

Sinclari-Maragh, G., Gursoy, D., \& Vieregge, M. (2015). Residents' perceptions toward tourism development: A factor-cluster approach. Journal of Destination Marketing \& Management, 4(1), 36-45.

Song, H., Dwyer, L., Li, G., \& Cao, Z. (2012). Tourism economics research: A review and assessment. Annals of Tourism Research, 39(3), 1653-1682.

Sun, J., Zhang, J., Zhang, J., Maa, J., \& Zhang, Y. (2015). Total factor productivity assessment of tourism industry: Evidence from China. Asia Pacific Journal of Tourism Research, 20(3), 942-953. 
Tang, X. (2017). The historical evolution of China's tourism development policies (1949-2013) - A quantitative research approach. Tourism Management, 58, 259269.

Torgerson, W. S. (1952). Multidimensional scaling: I. Theory and method. Psychometrika, 17(4), 401-419.

Torraleja, F. G., Vázquez, A. M., \& Franco, M. J. B. (2009). Flows into tourist areas: An econometric approach. International Journal of Tourism Research, 11(1), 1-15.

UNWTO (2015). UNWTO Tourism highlights, 2015 Edition. UNWTO (http://www.eunwto.org/doi/book/10.18111/9789284416899).

UNWTO (2016). UNWTO Tourism highlights, 2016 Edition. UNWTO (http://mkt.unwto.org/publication/unwto-tourism-highlights-2016-edition).

Upchurch, R. S, Ellis, T., \& Seo, J. (2004). Applying the hierarchical cluster analysis procedure upon the process of yield management-A comparative study. Journal of Travel \& Tourism Marketing, 16(4), 47-58.

Uysal, M., Chen, J., \& Williams, D. R. (2000). Increasing state market share through a regional positioning. Tourism Management, 21(1), 89-96.

Voges, K. E. (2007). Rough clustering of destination image data using an evolutionary algorithm. Journal of Travel \& Tourism Marketing, 21(4), 121-137.

Wang, Y. C., \& Pizam, A. (2011). Destination marketing and management: Theories and applications. Oxford: CABI.

Wang, Y. S. (2009). The impact of crisis events and macroeconomic activity on Taiwan's international inbound tourism demand. Tourism Management, 30(1), 7582.

Wish, M., Deutsch, M., \& Biener, L. (1970). Differences in conceptual structures of nations: An exploratory study. Journal of Personality and Social Psychology, 16(3), 361-373.

Wong, K. N., \& Tang, T. C. (2010). Tourism and openness to trade in Singapore: Evidence using aggregate and country-level data. Tourism Economics, 16(4), 965980.

Yau, O. H. M., \& Chan, C. F. (1990). Hong Kong as a travel destination in South-East Asia: A multidimensional approach. Tourism Management, 11(2), 123-132.

Yeomans, K. A., \& Golder, P. A. (1982). The Guttman-Kaiser criterion as a predictor of common factors. Journal of the Royal Statistical Society. Series D (The Statistician), 31(3), 221-229.

Zarate-Solano, H. M., \& Zapata-Sanabria, D. R. (2017). Clustering and forecasting inflation expectations using the World Economic Survey: The case of the 2014 oil price shock on inflation targeting countries. Borradores de Economía, 993.

Zins, A. H. (2010). Mapping beneficial destination images. Journal of Hospitality and Tourism Management, 17, 96-107. 


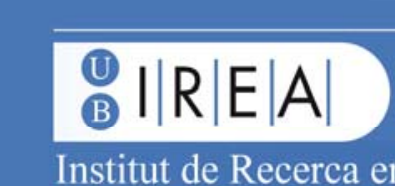

